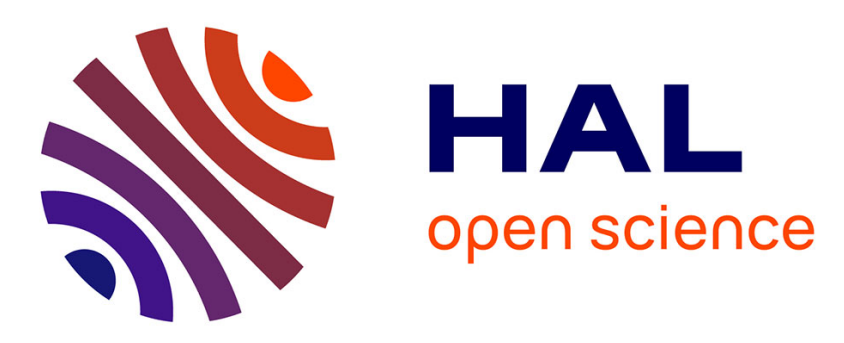

\title{
The effortful process of routines emergence: The interplay of entrepreneurial actions and artefacts
}

Aura Parmentier Cajaiba, Nathalie Lazaric, Giovany Cajaiba Santana

\section{To cite this version:}

Aura Parmentier Cajaiba, Nathalie Lazaric, Giovany Cajaiba Santana. The effortful process of routines emergence: The interplay of entrepreneurial actions and artefacts. Journal of Evolutionary Economics, 2021, 31, pp.33-63. 10.1007/s00191-020-00691-7 . halshs-02935713

\section{HAL Id: halshs-02935713 https://shs.hal.science/halshs-02935713}

Submitted on 10 Sep 2020

HAL is a multi-disciplinary open access archive for the deposit and dissemination of scientific research documents, whether they are published or not. The documents may come from teaching and research institutions in France or abroad, or from public or private research centers.
L'archive ouverte pluridisciplinaire HAL, est destinée au dépôt et à la diffusion de documents scientifiques de niveau recherche, publiés ou non, émanant des établissements d'enseignement et de recherche français ou étrangers, des laboratoires publics ou privés. 


\title{
The effortful process of routines emergence: The interplay of entrepreneurial actions and artefacts
}

\author{
Aura Parmentier Cajaiba, Nathalie Lazaric \\ And Giovany Cajaiba Santana
}

\begin{abstract}
Despite recent calls for processual analysis of routines creation, little work has been done to investigate the entrepreneurial mechanisms that explain the creation and adoption of new routines. This paper provides a processual contribution to the study of organizational routines by proposing a model for routine creation, based on an analysis of collective entrepreneurial actions. Using an entrepreneurial bricolage lens, we show how agents, during the creation of new routines, develop mechanisms to adapt firm processes, enact external constraints and validate novel practices. Our analysis is based on a three-year collaborative study in a French biotechnology firm. We develop a processual model of routine creation comprising three phases: scanning, performing and adopting. The model provides new insights into the interplay between artefacts and entrepreneurial actions in the creation of new routines.
\end{abstract}

\section{Introduction}

The study of organizational routines has emerged as an important aspect for explaining and understanding certain aspects of organizational behavior, stability and change (Cyert and March 1963; Nelson and Winter 1982; Feldman 2000; Feldman and Pentland 2003; Howard-Grenville 2005). However, the current research has failed to provide a compelling explanation of the process underlying the creation of routines (Cacciatori 2012; Dionysiou and Tsoukas 2013; Davies et al. 2018). Much of the previous research focuses on the replication of or changes to routines (Edmondson et al. 2001; Lazaric and Denis 2005; Labatut et al. 2012) and ignores the mechanisms associated with routine creation.

Over 30 years ago, Low and MacMillan (1988) highlighted the significance of understanding process, context and outcomes related to entrepreneurial actions. Since then, a great deal of research on entrepreneurship has been devoted to understanding how entrepreneurs make use of networks, knowledge and resources to create organizations (Busenitz et al. 2003). Some years later, in another field of organizational research, Pentland and Rueter (1994) suggested that routines should be analyzed in terms of being an "effortful accomplishment" and as a way of understanding organizational action. Although several calls have been made for processual and longitudinal analysis of the emergence and the evolution of routines (Labatut et al. 2012; Howard- 
Grenville et al. 2016), little progress has been made on understanding the entrepreneurial mechanisms that explain their creation and adoption. We try to fill this lacuna by identifying collective entrepreneurial mechanisms as generative systems capable of explaining the creation of routines.

To this end, we analyze the process of routine creation through a lens that has been ignored in past research: entrepreneurial actions. Studying entrepreneurial actions as mechanisms for the emergence of routines has been overlooked, in part, because most previous research focuses on established rather than emerging firms (Phillips 2005; Aldrich and Yang 2014). Mathews (2010), for instance, highlighted the significance of understanding how routines are created and how this process helps to provide a coherent, general account of strategic entrepreneurship. The notion of routine was used by Mathews (2010, p. 224) to define strategic entrepreneurship as “...the activity that drives the economy in new directions through recombination of resources, activities and routines by firms". Thus, by investigating entrepreneurial actions, we shed some light on the micro-foundations of organizational routines and their dynamics over time (as suggested by Felin and Foss (2009) and Winter (2003)).

According to Mathews (2010), the effortful actions of entrepreneurs bring routines to life and set them in motion. Since “...we still have much to learn about how process and context interact to shape the outcome of entrepreneurial efforts" (Aldrich and Martinez 2001, p. 41), our endeavor, here, is to understand the mechanisms that enable entrepreneurial actions to directly shape organizational routines.

Our study is based on a three-year collaborative research carried out at a small French company (which we will call Agronate) in the biopesticide industry, which has been subject to emerging new strict and complex regulation. We study the routine creation necessitated by the implementation in the European Union of new regulations requiring the registration of biological pesticide products. This has led to the creation, articulation and codification of new knowledge (Winter and Teece 1998; Winter and Szulanski 2001; Tell 2013) that has been exploited to implement new coordinating mechanisms that involve the creation of routines and artefacts (Feldman et al. 2016; Jarzabkowski et al. 2016; Feldman 2016). Our study provides an organizational example of routine creation to fit with the new regulation. This case is emblematic because it depicts a context in which 
neither replication of nor change to an already existing routine is possible. This implies that it is necessary to create routines using the resources available from the chemicals field and adapting them to biological products.

Our data suggest that agents involved in the creation of new routines engage in a collective bricolage behavior to create repertoires of resources based on dialogues with these resources, to produce new artefacts and routines. A theoretical bricolage lens helps to explain how patterns of action are created, selected and retained during the routine-creation process. It also allows us to map the process of routinization by analyzing interactions between agents and the artefacts created during the process.

We analyze collective entrepreneurial actions performed during this process and examine the involvement of agents in the creation of new knowledge and artefacts. This contributes to the literature on routines and entrepreneurship in at least three ways.

First, we propose entrepreneurial bricolage as a comprehensive theoretical framework, which includes theoretical agentic elements, to analyze the actions of agents faced with uncertainty and resources scarcity in the process of creating new routines. Second, we propose a routine creation model in a context that does not allow either replication of or changes to routines. This model is structured around three phases: scanning, performing and adopting. It helps to explain how patterning emerges from actions mediated by dialogue and artefacts (Feldman 2016). Third, we investigate the development of "speaking artefacts" (Cacciatori 2012) in routine creation and their role in learning and coordination processes.

By doing so, we are also contributing to combining the dynamic view of routines as a process, in which "they [the routines] emerge through their own enactment and in relation to other practices“ ( Feldman et al. 2016, p. 506 ), where stability is not a result per se but a real accomplishment' with the capability perspective for building skills and capabilities in relation to internal and external pressures. We thus try to make a contribution for linking these two schools with original empirical evidence by showing why these two streams of literature are fruitful for depicting such a complex and rich research setting (see also in this direction Parmigiani and Howard-Grenville 2011; Salvato and Rerup 2011; Howard-Grenville et al. 2016; Kay 2018) 
Our paper is structured as follows. Section 2 presents the theoretical foundations to our study, drawing on the notions of routines emergence, entrepreneurial bricolage and artefacts. Section 3 describes the research setting and the technological context of our data collection, and the methodology chosen. Section 4 presents the analysis and Section 5 discusses the empirical findings. Section 6 concludes the paper with a summary of the main findings and our research contributions.

\section{Theoretical foundations}

\section{Routines: an emergent process}

Feldman and Pentland (2003, p. 95) defined routines as "repetitive, recognizable patterns of interdependent actions carried out by multiple actors". Nelson and Winter (1982) highlighted firms' abilities to memorize individual skills and encode them in organizational procedures and routines to allow consistent responses to changes in the environment. Some considered that routines were embedded in the firm and its structures and were context specific (Cohen et al. 1996), while others considered routines as "emergent", and materializing through specific performance (Feldman 2000). Routines were seen, also, as "generative", producing stability or change through the actions they engendered (Rerup and Feldman 2011).

Arguably, a major turning point in research on routines was their conception as processual in nature (HowardGrenville et al. 2016; Bucher and Langley 2016). Simpson and Lorino (2016) proposed the pragmatist concepts of habit, inquiry and conversational transaction and demonstrated their potential to advance processual knowledge on routine dynamics. This idea has implications for the understanding of the organizational mechanisms underlying the emergence, change and stability of routines (Dionysiou and Tsoukas 2013). It extends the stream of research on "routine dynamics", which focuses on the actions of the actants (Feldman et al. 2016) and the patterns created through those actions that, eventually, acquire the status of routines (Cohen 2007). 
Despite the significance of routines for the functioning of firms, we know little about the process of creation and emergence of routines in organizational settings. Previous efforts have been focused on adaptations to or re-creation of routines (Edmondson et al. 2001; Lazaric and Denis 2005; Labatut et al. 2012).

Seminal works on routines suggested that activities associated with problem solving could be routinized "to the degree that choice has been simplified by the development of a fixed response to defined stimuli" (March and Simon 1958, p. 142). Later on, the structuration and pragmatic research traditions added to our understanding of organizational routines and demonstrated that routines are enacted by engaged and mindful actors and are not just mechanical responses to established rules or stimuli (Feldman 2000; Feldman and Pentland 2003; Howard-Grenville 2005; Salvato 2009; Rerup and Feldman 2011; Cacciatori 2012). In this respect, Bertels et al. (2016) showed that off-the-shelf routine integration is not a copy-paste activity, but rather an effortful social accomplishment. In particular, they analyze the work that must be done at the cultural level to adopt and perform a routine when there is little cultural fit. These works suggest that individual and organizational enactments are critical dimensions because routines are not set in stone, rather they are subject to change (Feldman 2000). They provide individuals and firms with the possibilities to learn, change and evolve to ensure stability.

In one of the first studies on routine emergence, Cohen and Bacdayan (1994) investigated the role of coordination in routines. They showed that routines emerge when two agents perform a task repeatedly, in a cooperative and coordinated way. However, they did not explain how the agents achieve the coordination that eventually spurs the emergence of repetitive patterns of action or routines. Others have suggested that it is necessary to consider socio-material perspectives to analyze not only actions among humans but also nonhuman relations (Orlikowski 2007; D’Adderio 2011; Pentland 2011).

The structuration and pragmatic traditions have demonstrated the importance of shared meanings and understandings among participants in the elaboration of a new routine (Turner and Rindova 2012). For instance, Zbaracki and Bergen (2010) showed how lack of communication and a shared understanding can cause the collapse of a new routine, while Miller et al. (2012) analyzed how agents'skills are combined in the creation of routines. Miller and colleagues assumed that routines are formed in settings where agents are faced 
with solving recurring similar problems. Reynaud (2005) studied how routines evolve from rules and procedures across internal coordination process. She conceptualized routines as strategies adopted by agents to achieve organizational goals, and argued that routines differ from rules in the sense that routines bestow pragmatic solutions and emerge only in the course of action. Dittrich and Seidl (2017) mobilized the meansends dialogic relationship following a pragmatist tradition to suggest that the means used to deal with immediate circumstances redefine the goals.

Dionysiou and Tsoukas (2013, p. 182) developed one of the rare theoretical models for the creation of routines "from within", although embedded in a broader context. They followed the pragmatist tradition by grounding their model in the relational aspect of agency i.e., the actions and understandings of the agents involved in the process of creating new routines. Their model is based on the assumption that new routines are created $e x$ nihilo or with few pre-established rules from managers or entrepreneurs and few local interactions among internal groups. These assumptions do not take into account the organizational contexts in which managers or entrepreneurs take an active role by using external models or templates in the elaboration of routines . Therefore, although the role of agency in routine emergence has been demonstrated (Howard-Grenville 2005; Bapuji et al. 2012), the role of entrepreneurial mechanisms and entrepreneurial actions as initiating routines creation has been mostly overlooked.

We share Mathews's (2010) idea that creation of routines is a tool that allows entrepreneurs to avoid uncertainty, conflict and resources scarcity. Casson (1982, p. 23) defined an entrepreneur as "someone who specializes in making judgmental decisions about the coordination of scarce resources”. Moreover, routines provide a sense of stability to the firm's modus operandi, which entrepreneurs look for during the firm's early stages of development (Stinchcombe 1965).

\section{Collective entrepreneurial bricolage and routine emergence}

Historically, entrepreneurship was understood as a creation of a firm under the control and hierarchy of an entrepreneur. However, new perspectives have been proposed, which apply to other contexts than creation of a new organizations (Stevenson and Jarillo 1990). For instance, Sharma and Chrisman (1999) defined 
entrepreneurs as an individual or group of individuals, who act either individually or as part of a corporate system, create new organizations or instigate renewal or innovation of an already existing organization.

The ideas of collective entrepreneurship (Comeche and Loras 2010), corporate entrepreneurship (Zahra 1993) and intrapreneurship (Parker 2011) invite analysis of entrepreneurship dynamics at lower hierarchical levels than top management, in already established firms. These approaches suggest that the degree of entrepreneurship in the firm depends crucially on the attitudes of individuals to the creation of newness. Our case involves a collective project of routine creation manifested as collective entrepreneurship (Comeche and Loras 2010), which emerged from synergetic contributions from internal agents facing uncertainty and scarce resources. The kind of behavior entrepreneurs enact when faced with unprecedented problems or new opportunities, or to deal with uncertainty and resources scarcity, has been theorized as entrepreneurial bricolage (Baker and Nelson 2005).

Therefore, we conceptualize the actions scrutinized in our study as entrepreneurial and analyze them through the theoretical lens of entrepreneurial bricolage. First, because the literature on entrepreneurship describes entrepreneurial action as purposeful behaviour in a context of uncertainty and, consequently intrinsically new (McMullen and Shepherd 2006). Second, because we observe that agents engaged in a collective entrepreneurial bricolage behavior, making use of scarce resources to create new organizational structures, face new problems and exploit new opportunities.

An entrepreneurial bricolage perspective suggests that agents manifest bricolage behavior by making use of scarce resources to create new organizational structures, resolve new problems and exploit new opportunities (Baker and Nelson 2005; Halme et al. 2012; Linna 2013). Levi-Strauss (1966) proposed the concept of bricolage to suggest the creation of something new from the combination and transformation of existing resources.

As a process, we can conceive bricolage as the creation of something from what appears to be "nothing" (Baker and Nelson 2005). Senyard et al. (2009) demonstrated the positive effect of bricolage on firm 
performance. Others have shown that bricolage is an appropriate theoretical lens to analyze social firms subject to institutional constraints or weak regulatory support (Di Domenico et al. 2010; Janssen et al. 2018).

Combination of resources is at the core of the concept of bricolage. Agents engaged in bricolage enact their environment and co-shape (Garud and Karnøe 2003), with other organizational agents, "what is desired and feasible with the resources they have at hand" (Janssen et al. 2018, p. 453). For instance, Desa (2012) argued that bricolage is not just about limited resources, but also and importantly is about transforming limited resources into useful output. This perspective provides the theoretical elements to analyze how routines emerge from entrepreneurial actions and mechanisms in a context of uncertainty and scarce resources, which applies to our case.

Levi-Strauss (1966) described bricolage behavior as based on three mutually constituting elements: repertoire, which is the 'stock' of resources available; dialogue, which describes the 'conversation' between the bricoleur and the resources to evaluate the kind of solutions possible with these resources; and outcome, which is the result of the process of bricolage. These elements provide explanatory power to understand the social mechanisms that lead to the creation of artefacts and, eventually, to new routines.

\section{Building routines and artefacts while inscribing knowledge}

Although the importance of artefacts was highlighted in early contributions to routines theory (Nelson and Winter 1982; Cohen et al. 1996), less research has been devoted to the influence of artefacts on routines creation and routines change compared to the role of agency in shaping routines. Some studies analyze how human agency is mediated by manmade objects (Orlikowski 1992) and investigate how agents create and make use of artefacts in their practice, to maintain or change routines (D'Adderio 2008; Salvato 2009; Rerup and Feldman 2011). D'Adderio (2011, p. 197) brought to the fore artefacts and their importance as providers of "the glue that can hold action patterns together" (p. 197). Later, Glaser (2017) demonstrated the importance of socio material assemblages of actors, theories and practices in designing artefacts to change routines.

Cacciatori (2012) suggests consideration of systems of artefacts rather than isolated artefacts, in the creation of routines. She demonstrated how the emergence of new routines is mediated by the development of systems 
of artefacts able to reproduce the problem solving structures at the heart of a reutilization process. Thus, artefacts should not be ignored in terms of how they articulate knowledge and transform potential skills for future capabilities (Lazaric et al. 2003; D’Adderio 2008; Cacciatori 2012).

Artefacts are a critical input, especially for the construction of standard operating procedures (Lazaric and Denis 2005; D'Adderio 2008). They mediate routines and skills and transform experience into potential capability (Cacciatori 2012), which draws attention to the micro-processes 'through which patterns of actions are created and recreated from within' (Dionysios and Tsoukas, 2013, p. 184).

Also important is the role of actors in designing artefacts and routines by inscribing their vision of ways of doing things (Glaser 2017; Davies et al. 2018). Artefacts encode knowledge and act as mediators between skills and routines (Cacciatori 2012). Artefacts are rarely used in isolation; rather, they are part of the systems important for stabilizing the firm structure. For instance, Lazaric and Denis (2005) discussed a quality handbook, which describes ways of doing things that rely on sub groups of artefacts or subtasks, such as codifying procedures and articulation of knowledge at each step in the process. Systems of artefacts are arranged and are mutually reinforcing to stabilize existing performance and identify appropriate patterns to co-shape routines (Cacciatori 2012). Indeed, speaking artefacts 'contain a visual representation of knowledge. They include procedure, manual, reports, technical drawings and virtual prototypes' (Cacciatori 2012, p. 1362) and include both the product and the process representation, i.e. the way things are done and how and why things are done in a certain way and why they make sense for the actors.

When organizations are faced with ill-structured problems and unstructured decision processes, the building of new routines may appear more complicated than initially conceived (Obstfeld 2012). In this case, there is a need not to replicate the initial knowledge or resources, but to find new coordination mechanisms such as bricolage. Replication is complex and implies some degree of novelty to redesign and adapt to a new context, since knowledge cannot be replicated and new knowledge has to be discovered (Becker et al. 2006). For instance, core knowledge (Arrow core) is discovered via knowledge articulation, which allows a better understanding of its content, limits and frontiers, i.e., what can be replicated and what needs to be redesigned (Gupta et al. 2015). Knowledge replication and codification depends on a process of knowledge transfer and 
transformation, which leads to negotiation of its core and adaptation of its scope (Lazaric et al. 2003; D’Adderio 2014).

Creating new routines is an effortful task, requiring templates to be built and the ostensive and performative levels to be co-shaped. This dual process conforms to a critical period of learning where the routines to be performed require the heavy involvement of actants in trial and error learning, experimentation and improvization to reduce uncertainty, while simultaneously articulating and trying to codify some of the knowledge.

Our objective is to analyze and understand the role of the entrepreneurial actions that support the creation of routines and the underlying role of artefacts, in a context of a paradigm change. We contribute the routines dynamics field by focusing on "actions" to provide parsimonious ways of theorizing the emergence of organizational routines. Making "action" an essential building block of the micro-level dimension of routines allows us to study the creation of new routines from an agency perspective as emerging from the "relationship between specific actions and patterns of action" (Pentland et al. 2012, p. 1485).

\section{Research setting}

Agronate is the pseudonym for a small biotechnology company, created in 2002, to develop biopesticide products. Biopesticides are pest control products based on biological entrants (bacteria, fungi, insects, etc.) and should not be confused with pesticide products that are made of chemical entrants. The biopesticide sector has developed as part of a wider, older and powerful industry, the phytopharmaceutical industry - the dominant paradigm in chemistry that influences the sector and its regulation.

Chemistry was the dominant paradigm for agricultural innovations (Possas et al. 1996). ${ }^{1}$ However, recently, new paradigms have emerged, such as genetic engineering and agroecological engineering, to challenge the usual ways of doing things (Vanloqueren and Baret 2009). The chemical pesticide industry emerged after

\footnotetext{
${ }^{1}$ Technological paradigms are the scientific principles and technology that apply to a given industry; they are "... as a 'pattern' of solution of selected techno economic problems based on highly selected principles derived from that natural sciences, jointly with specific rules aimed to acquire new knowledge and safeguard it [...] A technological paradigm is both an exemplar - an artifact that is to be developed and improved ....and a set of heuristics" (Dosi 1988: 1127), and show how these 'heuristics' are embodied in organizational routines.
} 
World War II with the development and introduction in agricultural practice of DDT (Handford et al. 2015). Pesticide regulation evolved as the industry developed. In 1947, the United States enacted FIFRA (Federal Insecticide, Fungicide and Rodenticide Act) as the first regulatory framework for the sale, distribution and use of pesticides. However, in Europe, regulation was imposed only in the 1970s. Prior to that period, registration of new products ${ }^{2}$ was not regulated (Handford et al. 2015).

Regulation, worldwide, evolved slowly towards stricter rules and more complex procedures, especially in the US and Europe (Handford et al., 2015). The largest phytopharmaceutical companies developed large registration departments and established consistent routines for elaborating and formatting information and communicating with the regulatory authorities.

The regulation of chemical pesticide activity in Europe became an institution within the industry. Biopesticide products have now been included in European Pesticides Regulation, which is based on the dominant chemical paradigm (Chandler et al. 2011). In 2006, the European Directive 2001-36 EC was transposed into the laws of all European countries. The phytopharmaceutical industry became the paradigm to regulate biopesticides. This was a shock to the small world of biopesticides; it meant that approval for commercialization was conditional upon compliance with the directive. It also confused the regulatory authorities, which had to consider new biopesticides in the absence of a framework to assess their specificities.

The regulation has acted as a barrier to biopesticide commercialization (Chandler et al. 2011) since its considerable costs are difficult for small biopesticides firms to support. To resolve this, new routines might streamline internal practices and internalize the registration process. Therefore, start-ups in the biocontrol sector should devote effort and resources to overcoming this change, selling their products and searching for and creating routines to allow compliance with the new environmental regulations (Hilliard and Goldstein, 2018). These firms tend not to create new practices, but rather to deconstruct and recombine certain subelements to create new ways of doing things through "entrepreneurial bricolage" (Baker and Nelson 2005). This allows them to cope with various tensions and constraints raised by a new paradigm (Vanloqueren and

\footnotetext{
${ }^{2}$ Registration refers to the process involved in firms obtaining regulatory approvals to sell their products.
} 
Baret, 2009). The creation of new routines, such as product registration, is a prerequisite for these firms' survival and growth, but requires the building of complementary resources such as artefacts for articulating knowledge and codifying some parts of it.

Agronate considered the subject to be sufficiently important to warrant recruiting a full-time researcher (Author 1) to work on the topic. The aim was to understand how to deal with the new regulation and how to create a routine related to obtaining product registration and approval and permission to sell its products.

We were able to show that routine creation is based on performing actions. The selection of, retention of and modification (variation) to those actions occur during their performance. This process produces a consistent set of actions (a pattern) that guides daily activities that eventually might become a firm routine.

\section{Methodology}

To study routines, Cohen (2007) suggested a pragmatic approach for conceptual and methodological reasons. Conceptually, the foundations of pragmatist philosophy allow us to move away from a mechanistic view of routines. Methodologically, "we need a revised and enriched methodological arsenal, one that allows us to benefit from the extraordinary discernment of human observation and participation without losing the possibility of convincing disconfirmation" (p.782). Cohen acknowledged that the logic to make "inquiry about inquiry' can provide methodological insights to study routines, and showed, as does Lorino (2018), that the concept of routine is at the heart of pragmatism, which points to the use of this lens. The present study follows an enquiry logic enabled by collaborative research requested by the firm.

Author 1 led a collaborative research (Shani et al. 2007) rooted in pragmatist philosophy (Lorino 2018), and that can lead to numerous dialogues among different protagonists (Author 1, 2018). The collaboration was defined so that Author 1 was responsible for developing the registration activity. Elaboration of this new activity led to the creation of routines new to the firm. Table 1 shows the consistency between the field and the research question. 
Author 1 (2010) was recruited to study the regulatory activity and develop knowledge and knowhow on regulatory logics. Since the firm and its agents knew little about the registration procedure, this corresponds to a pragmatist inquiry, as suggested by Cohen (2007). She followed the case for 4,5 years and carried out a three-year collaborative study. During this period, she collected diachronic situated data for 2,5 years such as email exchanges, interviews, research diary data, observation and participation during the actions she was coordinating within the firm. Between April 2005 and October 2007 (first period), she immersed herself in the firm to develop the registration activity, then she slowly stepped back from the field (second period) and began the analysis. During the period of analyses, she interacted regularly with the firm as a registration consultant. In June 2009, she concluded her links to the firm to complete the analysis and the writing of her dissertation. Author 1 kept a research diary (a logbook) of her working days throughout her engagement with the firm, recording all information related to registration and to her activities. This research chronology helped to ensure that, during the first period, she was totally invested in implementing the registration activity as an employee. During the second period, she took the stance of a researcher and distanced herself from the case in order to start the analysis.

This organizing choice presented certain challenges for the researcher. One of these involved making sense of the huge volume of data and selecting the relevant information. She used various techniques as visual maps and bracketing (Langley, 1999). She found it was difficult to interview people during the time she was working with them. As a result, the interviews were conducted one year after phase one. This allowed her to step back and to see how the activity was evolving after her intervention in the firm.

This type of collaborative research provides an opportunity to collect fine-grained diachronic process data. Diachronic data are related to the activity as it unfolds and allow a response to calls to study routines from a process perspective (Howard-Grenville et al. 2016; Simpson and Lorino 2016). 
Initially, data collection was aimed at understanding how a capability is developed. However, the data collected allow us, also, to understand the creation of routines, since these data constitute the building blocks of organizational capabilities (Cohen et al. 1996; Parmigiani and Howard-Grenville 2011; Davies et al. 2018). We drew on parts of the dataset to study the entrepreneurial mechanisms explaining the process of routine creation.

During this period, Author 1 was employed in the case firm as Registration Project Manager (PM) and was required to interact with scientists, technicians, engineers, managers and consultants to develop the registration activity and related routines. These interactions and exchanges occurred during formal and informal meetings and conversations, and emails. The email data provide a variety of information to analyze actions. The material is processual; thus, it allows identification of most of the actions related to the activity because a significant part of the communication was conducted via email. We were able to trace information exchanges, identify the internal and external actors concerned, and track the documents sent or received. These data also provide information on the firm's domains by specific actions or topics. The email database allowed us to conduct precise chronological analysis and to study how actions evolved over time and with what results.

Based on Author 1's activity, we constructed a database comprising 1,013 emails, which amounted to some 500 pages of written data. The emails allowed us to elaborate a processual account of the relevant entrepreneurial actions in the routine creation process; the emails provide information on what was done, how it was done and the limits to the activities.

Several routines were developed during the process of capability creation. We decided to focus on a metaroutine involved with creating a registration dossier. ${ }^{3}$ This routine was aimed at codifying the technical specificities of substances and products and the associated research and production processes. The codification must be consistent with the dominant chemical pesticides paradigm and must reflect the nature of biological Research and Development principles.

\footnotetext{
${ }^{3}$ The term 'dossier' is used by the regulatory authorities and by practitioners to describe the documents that firms submit to obtain product or substance approval.
} 
We identify the entrepreneurial actions at stake when developing a new routine and, in particular, the means used to create, change or adapt scientific procedures and organizational practices to fit the new regulatory framework. These actions are articulated into mechanisms and a process model of routine creation.

\section{Data Analysis}

We conducted an analysis based on categorization and connection of data (Maxwell and Miller 2008). This was aimed at providing a process model of how entrepreneurial actions are enacted to create new routines at the nexus of two paradigms. Based on our knowledge of the case, we categorized the data into three classes of actions involved in routinizing the regulatory activity. First, actions related to adapting the current structure (adaptation); second, actions related to enacting the regulatory principles (enaction); and third, actions aimed at deciding whether to adopt the practices of the chemical paradigm (adoption).

Based on this initial categorization, we carried out inductive coding of the email database (Charmaz 2006) to identify actions related to the three categories. We attributed each coded element to at least one category. Following this categorization process, we checked for redundancy of the codes created with similar labels in each initial category. We further elaborated the thematic tree by employing axial coding (Table 2).

\section{Insert Table 2 About here}

We used Nvivo 10 software to codify and relate each code to the chronology of the activity development. Once the tree was stabilized, we read the coded extracts carefully and linked the codes using an entrepreneurial bricolage lens to achieve relations that would lead to a process model. Our analysis relies on the bricolage theoretical lens to articulate the categories created during the coding process. These phases of the routine creation process highlight various roles taken by artefacts in an entrepreneurial bricolage process (Levi-Strauss 
1966; Baker and Nelson 2005) articulated around the notions of repertoire, dialogues and outcome. This allows us to detail the distribution of the entrepreneurial actions (codes) chronologically, to identify how activities unfold overtime and resituate entrepreneurial actions relatively. We conducted continual comparison between codes and the chronology of the activity development.

Below we describe and analyse the process of routine elaboration following the data chronologically, as an analytical and methodological tool allowing study of the phenomenon as processual and evolving over time.

\section{From new scientific paradigm to new routines}

Once the collaborative research had begun, the firm activity was related to scientific practice in biology and agronomy. However, although a large part of a regulatory dossier includes scientific work, firm scientific practices are not the same as registration scientific practices.

Firm scientists perceived their own practice as more legitimate than registration practice; therefore, the Agronate scientists had made no effort to try to understand how to implement the regulatory activity. The firm needed to integrate several different practices to create new routines that would produce scientific work consistent with regulatory requirements. In this context, Author 1, as an outsider to the scientific domain, engaged in a thorough inquiry to understand the nature of the regulatory activity and its links to the firm's scientific work.

Our findings show that the development of a new routine related to an activity that is different from the firm's core activities is based on three distinct phases: scanning, performing and adopting.

Scanning relates to the integration of new practices and new knowledge leading to the creation of artefacts that, eventually, will support coordination. Performing involves the actors tinkering with and testing ways of implementing a routinized activity, when artefacts support collaborative actions. During this phase, the interweaving of existing and new routines gives rise to conflicts based on resistance and misunderstandings. Adopting is characterized by the process of legitimation that leads agents to adopt, modify or reject elements of the new routine. Figure 1 depicts the three-phase routine creation model. It summarizes our main results and the mechanisms and actions that explain development of a routine. 
To avoid semantic confusion, our categories - adapt, enact and validate - are in bold, the codes are in italics and the bricolage elements - 'repertoire', 'dialogue' and 'outcome' - are in single quotation marks.

\section{Scanning phase: from new knowledge to using new artefacts.}

We label the first phase scanning because it reflects the fact that agents are involved in a process to understand the new activity, which requires creation of new routines. Our data show that agents engage in specific associated activities: practice integration, artefact creation and using artefact as coordination tool.

\section{Practice integration}

To develop a new activity, the firm actors engaged in bricolage behavior to adapt firm practices. Our analysis shows that this adaptation includes developing a network (network creation) to obtain information on the activity and develop activity-specific practices.

To understand registration, Author 1 as Registration Project Manager (PM) engaged in active inquiry. In this phase, this inquiry was carried out in isolation from the firm's core activity. It adhered to no specific guidelines; Author 2 used the 'repertoire' to hand in combination with 'dialogues' (with external actors, resources, and stakeholders) to develop a new base of knowledge (learning). Author 1 developed a network of key persons in regulatory institutions to engage in dialogue. This led to specific information required for the knowledge and practices of registration activity. The new resources became part of the firm 'repertoire'.

Network creation and learning are interrelated recursively to develop new practices. In this early phase, the firm engages cautiously in the new activity. In the extract below, note that the PM (Author 1) discovered and experimented with a practice that was new to the firm (Diagram), but is common in the chemical industry. 
Please find attached the diagram I will present tomorrow to [ministry of agriculture] [...] I would be glad if you could tell me what you think of it. (Email from Registration PM to a chemical industry expert).

She borrowed a tool from a 'repertoire' that did not belong to the firm and was keen to know whether it had been used as expected.

Network creation and learning were employed to convince top management that the adoption of new practices (practices integration) was important to achieve registration. In the extract below, the registration team proposed to obtain the support of the regulatory authority to develop a central artefact to adapt the firm to meeting regulatory demands.

I have a good contact with the UK [regulatory authority]. I talked to the Product Manager [of the UK Ministry] for products made of microorganisms. She was interested in receiving our dossiers for assessment and is ready to meet us [...] to help us achieve the final draft. (Email from Registration PM to Top management - 2.8.2006)

In this phase, integration of knowledge (learning) about the new activity serves both operational and strategic objectives. On the one hand, the new information obtained enhances knowledge about which networks, procedures and practices are related to the new activity. On the other hand, it is used to achieve strategic momentum by demonstrating the specificities and importance of registration logics and showing that the network is providing new resources for the development of the new activity.

Practice integration of the new activity was facilitated by the active engagement of a few agents involved in the development of the firm 'repertoire'. Practice integration is not a linear process; it is rather the result of recursive interactions between Network creation and the knowledge developed (learning), enabled by a succession of 'dialogues'. Practice integration is the first step towards artefact creation and constitutes part of the entrepreneurial actions to adapt the firm.

\section{Artefact creation}

New knowledge (learning) and the practices developed (practices integration) for the new activity lead to the creation of activity-specific artefacts (artefacts creation). These artefacts take the form of lists of contacts, specific project management tools, templates for registration, etc. They can be conceptualised as what 
Cacciatori (2012) calls "speaking artefacts", which contain "formal representations of knowledge in verbal, mathematical or visual form" (p. 1665). The creation of those activity-specific artefacts involves a larger set of people in the company, in particular, top management. At this stage of the scanning phase, the inquiry process becomes more collaborative.

Creation of activity-specific artefacts enacts regulatory principles into firm processes by relying on the 'repertoire' developed previously. Agents engage in various types of 'dialogue' to develop dedicated artefacts. We identify two of these dialogues: more generic ones, aimed at supporting decision-making at top management level (guidance); and more specific dialogues, aimed at clarifying (clarification) new elements (knowledge, tools, terminology, etc.) at the operational level.

In the extract below, the Marketing Director emphasized the importance of understanding the regulatory procedures to achieve a registration dossier:

You ask me the prerequisites for doing registration: knowledge of the procedure is key to save a lot of time. I found ridiculous the time spent to writing the reports [for the first registration] so this is the typical example [of not having the knowledge]. (Marketing Director, post-collaboration interview - June 2008)

Both of the types of dialogues described above contribute to refining the artefacts to fit the firm's strategic objectives and operational constraints. New ideas and new knowledge about the new activity diffuse through the firm and increase the firm's repertoire by adding new activity-specific elements.

In the verbatim below, Registration Director obtained information (guidance) about how to get external support to develop artefacts to implement the new registration activity:

[...] the [UK regulatory department] has introduced a permanent scheme [artefact] to facilitate/encourage the registration of "biologicals" and they are eager to help and in fact were very helpful to one of our [federation name] UK members in the recent registration of a [substance name] product. (Email from Producers federation (UK branch) to Registration Director - 5.7.2006)

Thus, dialogues with external organizations are a means of obtaining information that helps structure the firm towards a new activity, i.e. to enact a new activity principle in the firm's processes. 
Dialogue between firm members reflects the work carried out to enact the activity into the firm's processes. The email quoted below shows that activity-specific artefacts question the firm's activity and initiate guidance dialogues:

What I call the Corps Files (the file template including each step) are completed. The constitution of this work tool leads me to ask myself several questions, some relating to quality controls $[\ldots]$ and also questions on the content of the files $[\ldots]$ and questions on the priority topics. (Email from Registration Team to Top Management -9.8.2006).

Elaboration of a specific artefact raises questions about both operational (quality and dossier content) and strategic (topics that must be treated first) issues. It invites top management to prioritize among several activities. The extract below shows that clarification dialogues describe use of an activity-specific artefact and how to adapt it to firm's needs.

[...] Concerning confidentiality, there is a part of the dossier [artefact] for sensitive information. An exception, [X studies] cannot be considered as sensitive $[\ldots]$ otherwise production processes are generally considered as sensitive $[\ldots]$ of course other kinds of data can be included as confidential. Overall [civil servants] are submitted to [Non Disclosure Agreement]. (Email from Registration Team to Top Management - 22.8.2006).

The situations described above show that clarification and guidance dialogues influence artefacts creation. Dialogues question usual activity and suggest changes to organizational habits. They contribute to increasing the firm's repertoire with more adapted artefacts. Rather than being an entrepreneurial activity, oriented towards a clear goal and supported by a visionary individual, we observed that entrepreneurial actions referred, here, to a collaborative inquiry, involving actors at both the center, and the periphery of the firm.

\section{Artefacts used as coordination tools}

Eventually, artefacts support coordination actions at both the strategic and operational levels. Overall, coordination of activities is carried out at the strategic level (strategic coordination). Artefacts retrieved from the firm's existing repertoire are used as coordination tools in dialogues with strategic and operational agents.

Artefacts contribute to linking core activities with the new activity. An artefact (Excel file) described in the extract below incorporates both regulatory demands (detailed explanation) and firm specificities (firm products): 
As defined yesterday, you'll find attached an excel file that sums up the tasks to be done and persons responsible for it. You can use it to write up your part. The Excel file is constructed around 5 sheets: one with detailed explanations and the 4 others for each product. (Email from Registration Team to RD, production and industrialisation Teams -30.8.2006)

By changing the organizational coordination mechanisms to adapt to the regulatory activity, the creation of dedicated artefacts promotes a new way of coordinating work.

At the operational level, daily coordination actions (operational coordination) include demands specific to the new activity. In the extract below, the Registration PM involves a third person in the task, to optimize the activity:

Can you formalise [production process] in the [dossier template] I sent you at the end of August? You are the right person to detail its implementation. It should be written in English (or French). Can you please see with C. the related quality control implementation... (Registration PM to Production PM - 6.11.2006).

The following extract concerns the organization of the firm (strategic coordination) towards the presentation of a dossier. It is aimed at ensuring that the different firm domains are aligned.

For the [externally carried out] studies: bee, worms, other arthro [pods] and algae, it is almost complete. The intratracheal acute tox[icity] is being carried out. We [consequently] think that the dossier can be submitted in March. Does that sound feasible with regards to the studies that you are carrying out? (Registration Team to R\&D PM - 28.11.2006).

The following extract shows how regulatory demands drive internal activity by inviting R\&D to redefine its priorities. The message from the CEO to all firm teams makes it more salient:

You'll find attached the minutes of the meeting held on Jan the 20th in [place of one of the firm's facilities] that lists the "details" [ironic way to talk about studies lacking] that must be finalised. You must take into consideration that [registration PM] needs all the [content] either in English or in French before Feb the 20th to be able to achieve the edition of the consolidated dossier [for submission] for March the 10th [...] 2007, not in 2008! I do not need to remind you of the strategic aspect of this submission [it is] a crucial need for our company to get this first registration, it is consequently also in your interest. [...] If you feel short in time, do not hesitate to speed up. (from CEO to R\&D directors and teams with copy to Registration -2.2.2007). 
In the scanning phase, the inquiry slowly becomes collaborative and provides activity-specific knowledge and artefacts. The firm's repertoire gradually increases with the integration of activity specific artefacts and knowledge.

An extract from the interview with the Marketing Director is illustrative of the coordination aspect of registration:

If you want [to construct a dossier], there has to be a permanent dialogue between homologation [and the other firm departments] because registration is a separate profession, it is a bit like patent drafting, you know? [there is] an administrative side. Which requires a profile to do that, like[...] in law or in legal. And at the same time [it requires] creativity.... So, once the approval process begins, you open the file, and from that moment on, the marketing department says: "yes, there is a real need for this crop", and as soon as the research says "yes, I have something that will hold up well". But we must [...] prioritise things correctly, so that we do not make people work anyhow and so that, as soon as the first studies are done (tox, the first drafts of biological activity etc. are available) the file can start. (Marketing Director, post-collaboration interview - June 2008)

The end of the scanning phase is a turning point in routine creation. It sets in motion the new routine development activity. In the next section, we describe the performing phase, which corresponds to the first performance of a future routinized activity, aimed at constructing an effective registration dossier. In addition to artefact creation, use and coordination, our data show that dialogue leads, also, to new forms of codification. The new elements of the repertoire together pave the way to a pattern of new routines.

\section{Performing phase: enacting new principles within the firm's processes}

In the performing phase, entrepreneurial actions are aimed at enacting regulatory principles into the firm's processes. This phase is characterized by codification of new knowledge (codification) and coordination of daily activities (daily coordination). Enacting new principles also reveals inconsistencies and conflicts between the established and the new activities. We next discuss the enaction of regulatory principles that arise from the processes of codification and daily coordination activity.

\section{Codification process}

The artefacts developed during the scanning phase are included in the firm's repertoire to contribute to the routine creation and the first performance of the (not yet routinized) activity. The new artefacts add to the 
codification of new knowledge (codification), which process is based on the dialogues conducted to clarify (clarification) the meanings of the rules associated with the new activity.

The following message is illustrative of the type of dialogue among the registration team to explain a specific registration activity (list of references). They explain what it involves and how to codify it to adhere to the regulatory requirements.

We will have to transmit the complete list of references [...]. The term 'list of references', [has a particular meaning] for European authorities. It includes not only scientific articles, but also other documents that support our demand (study report, study protocols, laboratory guidelines...). In order to achieve the final dossier, I thank you for grouping each element that supports our demand and listing each of them with the corresponding information (part of the dossier it refers to: Authors, Date of publication [or Date of realisation for study], title, level of confidentiality required and document ownership), Best... (Registration Team to R\&D Team and Dir - 27.11.2006)

This artefact constrains agents to adopt the new activity, which includes rules related to organizing the new workflow. Use of this artefact implies modifications to the firm's existing practices by the firm's scientists.

The extract below is from the R\&D Project Manager's description of the problems related to registration for her job:

$[\ldots]$ then it's very complicated too, well, I'm not in charge of the registration files, but for sending samples and doing analyses, well it's complicated. It's still really.... It's pretty complicated. To have a really complete dossier, well tied up,... It's really very strict. (R\&D Project Manager, post-collaboration interview - May 2008)

The next extract exemplifies the articulation between the creation of an artefact to fit the firm's existing activities. The dialogue describes the role played by these artefacts in the firm's daily activities (artefact in use). The artefact presents the firm's scientific work in a way that complies with the regulation:

As indicated by [Registration Director], I am constructing formalised documents that can provide support to your daily activities. These documents correspond to study or test report. [European] commission asks to join each [study report] with an administrative part. Hence, I decided to create this ad hoc template. (Registration PM to R\&D team - 17.11.2006).

In both cases, the changes to how scientific results are codified corresponds to adaptation of the firm's processes. Activity specific-artefacts guide the way the information is codified (codification). They affect not 
only task prioritization but also how the work should be conducted. In some situations, enaction of regulation is strict, while in others it takes account of existing daily activities. The interview extracts show, also, that process modifications are not driven by $\mathrm{R} \& \mathrm{D}$ but by the registration team.

New artefacts imply new codification habits, which affect local scientific practices. During the scanning phase, artefact creation had no effect on the firm's daily activities; it only increased the firm's repertoire. However, first performance of the activity has an impact on the firm's existing practices. The next section describes the effect on daily coordination, and the tensions and conflicts it created.

\section{Daily coordination}

Daily coordination refers to very specific exchanges about on-going projects. Our data show that daily coordination is supported by artefacts, as shown previously, and by specific and detailed dialogue between agents from different occupational domains. These dialogues are activity specific and are aimed at clarifying (clarification) particular points to ensure that all the actors have the same information; thus, clarification dialogues facilitate daily coordination mechanisms.

The extract from an email, set out below, shows that the registration team linked the firm's scientific knowledge to what the regulatory authority considered to be scientific proof. In this case, daily coordination concerns the firm's scientific activity:

For the [substance X dossier], C. evidenced 3 kinds of [substance]'s enzymatic activity mechanisms. The fourth one is currently under study. These experiments evidence the mode of action $[\mathrm{X}]$. It is currently the only mode of action that we could provide evidence for [in the dossier]. The other modes of action need to be studied through other experiments. As per our knowledge, it was not yet programmed, can you confirm it? (Registration Team to R\&D Team Registration Director - 12.12.2006)

Daily coordination is evident, also, in dialogues offering guidance about how to achieve what is required. The registration team uses these dialogues to orient action. The following extract shows that guidance dialogues take the form of information provided by an expert consultant to the registration team, to verify and confirm actions: 
$[\ldots]$ the list of toxicity studies that you are about to launch is correct, knowing that all this study must be carried out on the [final formulation] but the acute intra-dermal toxicity that must be carried out on [active substance]. Concerning sensitisation test, I do think that [test name] is more sensitive and better accepted by authorities. However, if you choose [other test name], it is preferable to ask the laboratory to detail the number of applications [...]. (From Registration Consultant to Registration Team - 2.1.2007).

In the next extract, the guidance dialogue takes the form of advice from the registration team to the R\&D team. It shows that registration influences how studies are conducted:

"Concerning C., I asked her to precise the study results on [entity 2] (and it was hard, she maintained that it was clear enough for her). She is supposed to supplement it with variable temporality at [level of temperatures] to determine the time lag for [substance] to be inactivated [at this temperature]." (from Registration Director to Registration PM - 16.1.2007).

Specific dialogues conducted during the performing phase contribute to changes to daily coordination processes, by either providing or obtaining information and explanations which are useful for enacting the new activity into the firm's processes. They change the conduct of the firm's scientific activity and become a part of the firm's daily coordination processes.

These changes are not without consequences and cause tensions and conflicts. The parentheses in the above extract show the difficulty involved in convincing agents to change their practice, while the new activity calls into question the firm's original practice.

In the interview extract below, the registration director talks about what registration is, and the difficulty involved in persuading other members of the firm to contribute:

"And about what is registration, it is a bit like sales, [it concerns everyone]. That is to say that elaborating a registration file, you have to have a product with a manufacturing process, you have to have the research people who have done a number of things,... anyways. We need to have efficacy dossiers written, or at least efficacy tests that are in line with the expectations of the authorities, [.... I am responsible for approval, but I have the impression that others do not feel concerned. They want the result but do not feel concerned by the elaboration." (Registration Director, post-collaboration interview - April 2008)

Integrating new practices creates a misfit between agents' usual practices (occupation and education based) and the practices embedded into activity-specific artefacts. Although R\&D staff are aware that registration is compulsory, as insiders to the firm's scientific activities, they are unaware of the importance of the formal 
presentation and the processes imposed by the regulatory authorities. The interview extract below describes the frustration felt by the firm's scientific staff, who perceived the registration staff as illegitimate.

$[$ R\&D PM] took that but really very, very, very badly, saying, [...] 'How about people who didn't do a thesis, who didn't do a bench? Who do not know what the fungus is, can write a dossier about microbiology'. That's how she took it. And she thought to herself. "I send them stuff and they, how they don't know anything about science, and they do what I did again and why the commission asked them to do it. (R\&D Director, post-collaboration interview - April 2008)

The performing phase worked to incorporate in the firm large parts of the routine, but also revealed conflicts. In the next section, we discuss two kinds of conflicts and tensions and how their resolution led to adapt firm's processes and to validate external practices, to facilitate acceptance of the routine.

\section{Adopting: adapting firm processes and validating external practices}

Adaptation of firm processes is evident in the changes made to codification practices (new codification) in an effort to resolve the remaining internal tensions. Validation of external practices through dialogue leads to adjustments to external codification practices to the firm's specificities (knowledge extension).

\section{Adaptation of firm processes}

The extract below is taken from a clarification dialogue aimed at resolving a longstanding tension. It concerns the regulatory formalities to which the $R \& D$ team is reluctant to comply because they are perceived as neither important nor legitimate:

C: "A question: is it necessary for each study to systematically detail in the appendixes the mother spawn production with the commentaries on the confirmation of the strain and its purity?" (From R\&D PM to Registration PM - 31.1.2007).

A: "[...] yes, it is necessary because the studies are not incorporated in the same parts of the final dossier. [Dossier parts are sent to different experts] and it is very likely that our studies will be verified by different persons. It is thus necessary to be precise with every instance of batch production detail.” (Registration PM to R\&D PM - 1.2.2007).

In this exchange, rather than refusing to perform the task, the R\&D PM asks whether it really is necessary; she opens the door to a constructive dialogue, which allows the Registration PM, eventually, to explain why it is necessary (new codification). The Registration PM had not explained this initially, because, to her, it 
seemed obvious. She knew how the new activity was structured and had not realized that the other agents might perceive some demands as pointless or too demanding.

If misunderstandings about regulatory formalities persist over time, engaging in constructive dialogues can lead to acceptance of external codification (new codification) which enriches the firm's repertoire (knowledge extension). Practices related to scientific form and not scientific content are adopted without modification. This leads to adapt the firm codification processes (new codification).

Internal conflicts arose when regulatory demands were technically inconsistent with the firm's activities. In the example below, dialogue helped to articulate the constraints associated with two different activities and achieve agreement. It shows that using chemical terminology (“...is determined to be $100 \%$ pure...”) was inconsistent with the biological domain. In similar situations, dialogue can lead to development of new ways to respond to regulatory demands by proposing alternatives to present the firm's specificities in a dossier (knowledge extension).

You point out that [the sentence] “...the formulated product is determined to be $100 \%$ pure...” [is inconsistent with our Active Substance] does that sound better if we write "... is determined to be free of other microorganisms and metabolites," does that make sense? We could also write: “...the production process is determined to achieve a product free of contaminants. (Registration team to R\&D Team and Dir - 12.12.2007).

We can see that the Registration and $R \& D$ teams engaged in a guidance dialogue to find a way to present their data that fitted with the firm's core activity and met the regulatory authorities' expectations. This adaptation was aimed at ensuring that the dossier would be evaluated positively. It again modified the firm's repertoire by developing new know-how related to the new activity (knowledge extension).

In the adopting phase, dialogue serves to provide an orientation if the new activity constraints are considered inconsistent or useless by the firm's agents. The output consists of adaptation of the firm's processes by reinforcing the validity of the new activity.

Validation of external practices 
Along with entrepreneurial actions of adaptation of firm's processes, validation of external practices was evident in the adopting phase. The repertoire of the new activity is reinforced by the interventions of external actors: consultants, authorities and experts. Their intervention strengthens the knowledge base (knowledge confirmation) related to how registration must be performed by aligning the routine's outcome (registration dossier) to the regulatory authorities' expectations.

The next extract shows that, since chemical institutionalized guidelines of non-environmental contamination were inconsistent with the biological domain (technical inconsistency), the firm adopted some external practices, combining them with internal studies (knowledge extension). The members of the registration team, along with the consultants, made the decision to combine several internal studies to provide evidence of noncontamination of the substance. This provides evidence related to justifying demands that are technically inconsistent with the firm's specificities (knowledge confirmation and extension).

[...] [in order to fit the regulatory framework] this study was realised in two parts: an efficiency test carried out by [partner's name] of which you have the report and a soil sample analysis carried out by $\mathrm{C}$. We decided that we would put [partner] study report in annex of the overall study. (from Registration Director to Registration PM - 17.6.2007)

When the regulatory demands were technically inconsistent with the firm's domain, adjustments were achieved through dialogue among various agents in the firm. In that case, the firm actors cooperated with external actors to elaborate the 'adjustment' to make the firm process fit the regulatory requirements.

\section{Discussion}

Our findings contribute to the literature on routines by describing collective entrepreneurial actions and mechanisms that explain the emergence of new routines in the context of a paradigm change.

Our findings show how a routine creation process can trigger collective entrepreneurial bricolage behavior, and how the success of such endeavors is contingent on the group's ability to create repertoires of resources and to engage in constructive dialogue with these resources. These findings contribute to our understanding of how entrepreneurial logics can explain the creation of new routines in already established firms (Halme et al. 2012). We provide empirical evidence that supports the theoretical model proposed by Duymedjian and 
Rüling (2010), who suggested that bricolage behavior can be successful in collaborative endeavors if agents are able to share each other's repertoires and engage in constructive dialogue.

We identify three categories of actions aiming at adapting the firm structure, enacting the dominant paradigm and validating elements in the firm's processes. Our processual model includes three phases. The first is scanning, the second is performing and the third is adopting.

The scanning phase of routine creation is aimed at understanding the dominant paradigm to allow the implementation in the firm of the related activities. It implies accumulating knowledge that will be incorporated into the new artefacts. In this stage, the bricolage behavior starts to take form: agents involved in the routinization of the new activity look to create a repertoire based on the resources at hand. They engage in successive recursive networking and learning efforts. The creation of the knowledge base and associated practices (repertoire) corresponds to adaptation to the firm's processes and becomes the base from which to develop the artefacts that will support performance of the routine. Replication is complex and implies some degree of novelty in the form of redesigning and adapting to a new context because knowledge cannot be replicated but must be discovered during this process (Becker et al. 2006).

This learning process has been observed in various entrepreneurial endeavors. Indeed, the most frequent sources of entrepreneurial learning are previous work experience, imitation and expert advice (Aldrich and Martinez 2001). It is in line, also, with Davies et al.'s (2018) routine creation model, in the sense that initiating a new routine is facilitated by external information search. Our model articulates the creation of a repertoire of knowledge based on external resources and their effect on the firm's adaptation to external constraint. In contrast, Davies et al.'s (2018) model is oriented towards the creation of new routine as a firm choice. The repertoire created using external resources is coherent, also, with a bricolage perspective. Vanevenhoven et al. (2011) suggested a distinction between internal and external bricolage. Internal bricolage relates to the repertoires created from the individual experience of each agent, while external bricolage includes the combination of the resources in the firm's external environment. In similar vein, Witell et al. (2017) highlighted the importance of "networking with external partners" as a specific bricolage capability. 
Pentland $(1995,2003)$ pioneered the routine field by decomposing observable routines into constituent components, thus portraying routines as sequences of "moves" with potential combinations. This implies that organizational members structure these diverse parts from inside and outside the organization, according to diverse feedback (Greve 2008). They test elements, select those that fit the environment and, progressively, create and recreate ways of doings things, necessary to legitimize their practice. This adaptation and learning is vital in the context of existing technological environments that co-shape the ostensive and performative part of routines.

The elaboration of artefacts emerges through engagement in successive new recursive action loops, which we label guidance and clarification. They correspond to the idea of dialogue in bricolage theory. These actions help the firm to adapt through an on-going process of repertoire creation, in terms of network (networking) and knowledge (learning) related to the chemical paradigm.

In focusing the analysis on actions, our model helps our understanding of the emergence of artefacts as well as the "agencies that are involved in their production and use" (D'Adderio 2011, p. 222). Artefact creation is aimed at embedding the dominant paradigm in the new artefact, hence it is a means of enacting the regulation in the firm's working resources. Once the artefact has been developed, it becomes part of the firm's resources. This new resource is the first output of the bricolage process and participates in the strategic and operational coordination required to prepare for the performing phase.

In their model of routine creation, Davies et al. (2018) showed that actions, at different organizational levels - top management and operational - foster routine creation. Our data show that coordination mechanisms are associated to both of these levels. The first level aims at ensuring the consistency of the overall process of routine creation and corresponds to the strategic level. The second level aims at enacting the dominant paradigm in the processes related to operational coordination. In line with Davies et al. (2018), we observed that the activities carried out during the process of routine creation could be strategic or operational. However, the actors carrying out the two activities are not necessarily different. 
We noted that, in the early stages of development that internal actors engaged in bricolage behavior from the outset. They start creating their repertoire of resources through the actions of networking and learning, to establish a dialogue with these resources (Levi-Strauss 1966). This is in line with Aldrich and Yang (2014), who observed that "entrepreneurs who begin with inadequate knowledge or experience will feel strong pressures towards learning by doing" (2014, p. 60).

Our findings build, also, on Edmondson et al. (2001) and Lazaric and Denis (2005), by showing that integrating an off-the-shelf routine is not a systematic top-down activity. Alongside management's role in fostering team motivation, securing employees and providing training, our study shows that the autonomy granted to employees facilitates the creative developments related to how to do things.

Previous research showed that performing and patterning of routines are facilitated by verbal interaction. Dittrich et al. (2016) pointed to the importance of reflective talks that « spur collective reflection and facilitate routine change" (p.22). Their study showed that reflections, expressed aloud among several actors involved in the routine, help to adapt performance of the routine and introduce changes to its patterning. Similarly, using the lens of entrepreneurial bricolage, we observed that dialogue, spoken or written, has an important impact on routine creation. The dialogues that occurred during the scanning phase, involving agents not part of the activity, proved crucial for driving development of the new routine. First performance of the routine relied heavily on various types of dialogue (from friendly exchanges to cathartic discussion), which took place during the scanning phase. Those dialogues contributed to patterning/performing recursive relationships similar to what Dittrich et al. (2016) described.

We noted, also, that the early stages of routine creation may be initiated by a few individuals with few resources. This finding is counterintuitive, since the field of routines creation emphasizes the collective nature of routines (Nelson and Winter 1982; Feldman 2000; Feldman and Pentland 2003). Another intriguing finding is that the repertoire developed is used subsequently during the performing and adopting phases, but the actions carried out to develop them are not aimed at their reproduction during routine performance. 
The scanning phase reveals the boundary conditions and the recursive nature of the ostensive-performative and patterning-performing aspects of routines. Indeed, if routines need to be developed without replication or changes, our findings show that a first creative step is necessary to set in motion the basic mechanisms, which will nurture those recursive routine dynamics. In this context, entrepreneurial bricolage is a suitable theoretical framework to analyze the process and, especially, its initiation.

Both our and Davies et al.'s (2018) models present the creation of artefacts as supporting the routine creation process. Davies et al. (2018) analyzed the influence of different organizational levels, capabilities and logics for shaping organizational routines. For instance, they showed that the process of routine creation is grounded in propositions from top management of a theoretical ostensive aspect of the routine that will be anchored to an artefact. In our case, the routine creation process is associated not with an ideation process fostered by information obtained both from inside and outside. Rather, the knowledge and network developed about a dominant paradigm provide a base for the creation of an artefact. The rules of the dominant paradigm are embedded in an artefact and, as such, affect adaptation of the firm's processes, in the sense that the artefact implies new coordination mechanisms to steer the firm towards performance.

The most salient features of entrepreneurial actions are that they are purposeful and new and must face uncertainty and risk (McMullen and Shepherd 2006). One of the main roles of routines in the entrepreneurial process is to structure organizational action in order to reduce the risk and uncertainty inherent in entrepreneurial endeavors. Our analysis shows that, in the process of routine creation, promoted by a paradigm change, agents make use of entrepreneurial bricolage to develop networks and acquire the necessary knowledge to integrate external pressures. Previous research argued that, based on the entrepreneur's abilities and on random events that reinforce existing beliefs, entrepreneurs learn in unpredictable ways (Minniti and Bygrave 2001). Our case shows that this "unpredictability" is not the main characteristic of the learning process even though bricolage implies uncertainty. The development of networks and artefacts aimed at the creation of knowledge is a process that becomes more and more structured as it evolves.

The second phase of our model shows that the process of routine creation is based on performing new activities exploiting previously developed artefacts. These new activities represent complex adaptations to old schemata 
and new practices, based on trial and error (Rerup and Feldman 2011), to achieve the development of the future routine. This phase is characterized by a series of entrepreneurial actions and mechanisms, which contribute, simultaneously, to adapting the firm's processes, enacting the dominant paradigm and, eventually, validating the use of practices pertaining to the dominant paradigm.

The artefact developed during the scanning phase becomes an input for the performing phase. The enaction of the chemical paradigm started with the use of the artefact. This enaction was realized by engaging in a more structured process of codification, which enlarges the agents repertoire. Bricolage behavior is perceived in a new light, since use of the artefact implies adjustments and conflicts that are new to the firm and are managed using "whatever is at hand" (Baker and Nelson, 2005, p.333). The communication mechanisms, which we coded as guidance and clarification, are based on the bricolage principle of dialogue, in which agents try - often through trial and error - to find the best way of passing on information and understanding and integrating chunks of information from different repertoires.

Relying on a pragmatist view, Dittrich and Seidl (2016) tackled the means-end dualism in routine performance. In contrast to studies that focus on the impacts of ends and means in routine performance (Howard-Grenville 2005; Rerup and Feldman 2011; D'Adderio 2014), Dittrich and Seidl showed that means affect the objective of the routines, i.e., new ends-in-view. Our findings contribute to this situated view of routines. We show that the routine creation process relies heavily on artefacts mediated by dialogue; these artefacts can fulfil two roles. Depending on the situation, they can be viewed as goals (ends-in-view) or as means (a spreadsheet, a database, etc.). In the scanning phase, when neither a dedicated tool nor a network exists, artefacts are ends-in-view: they are something that agents look for or try to create. Once created, artefacts become a means to achieve new ends-in-view. For example, a document becomes a coordination tool to organize the registration activity to be developed. Therefore, studying routine creation, in particular, shows that means and end-in-views are not fixed, but are especially "fluid and flexible" (Dittrich et al. 2016) at the time of the routine creation because the elements are in a process of becoming (Tsoukas and Chia 2002). In this situation, agents define the artefacts of the activity in the making based on what they anticipate regarding occurrence of the activity. 
Levi Strauss's bricolage framework of 'repertoire', 'dialogue' and 'outcome' framework also echoes the idea of agency proposed in Emirbayer and Mische (1998). The bricoleur engages in a dialogue (in the present) with a repertoire that the bricoleur has developed over time (based on previous experience and experiments) to achieve an outcome (end-in-view). Both dialogue and repertoire are means to realize the outcome, and the outcome can integrate the repertoire once it becomes an end-in-itself or a fixed end; as such, they also become new means.

During the last phase, the repertoire and outcome created during the scanning and the performing phases become inputs for the adopting phase. During this last phase, we observed that coordination work is done to achieve legitimacy. At this point, the codification process is established among they key agents who share a common repertoire and conduct dialogue to achieve a legitimate outcome.

In our study, the inquiry focused particularly on agency. The notion of agency proposed by Emirbayer and Mische (1998) relied on pragmatism to develop the idea of agency in relation to time. The notion of a chordal triad of agency, in particular, resonates with our findings because it associates agent actions to past patterns, future expectations and the ability to respond to the "emerging demands, dilemmas, and ambiguities of presently evolving situations." (p. 971). We show that the development of artefacts as ends-in-view is consistent with both past definitions (regulatory demands) and the firm's future expectation (obtaining approvals) and is developed following the situation's current constraints and possibilities. The use of artefact as coordination tool arises in that present situation to allow advance towards an ideal future situation (developing a new activity that is in line with the firm's needs) and borrows from past situations (existing norms from the regulatory domain). Eventually, validation of the elements that will constitute a new routine is legitimated because they fit with both past constraints (regulatory norms) and expectations (developing new products).

Consistent with Cacciatori (2012), our findings show that when routine replication or change is impossible, the creation of artefacts is a necessary step towards new routine creation (scanning phase). In this context, the creation of the first artefacts gives substance to the new activity to be routinized (in our case, the regulatory activity). Artefacts make the activity more concrete for the agents who will be engaged in performing the 
routine in the future, and this is especially important if the new activity is remote from these agents' own occupational concerns.

\section{Conclusion}

This study is one of a very few empirical and systematic attempts to map the entrepreneurial actions leading to the creation of routines. We observed the emergence of routine at the intersection of actions and tensions from within and as a product of knowledge discovery and knowledge articulation that occurs during the process of building artefacts for inscribing it. Artefacts play a critical role by mediating among representations of possible new ways of doings things, and constitute the resources for building new capabilities.

We have provided empirical evidence from an analysis of entrepreneurial actions observed when paradigms conflict, which destabilizes current practice and leads to the emergence of a new routine. We identified and characterized the entrepreneurial mechanisms related to old and new heuristics. Identification of this mechanisms leads to a better understanding of the underlying forces fostering the emergence and legitimation of a new routine.

The investigation in this paper suggests directions for further research. For example, we examined the role of dialogue in routine creation quite superficially; more in-depth analysis of dialogue would advance our understanding of its role in routinization. In particular, we believe that it is important to identify different types of dialogue and their roles in the scanning phase which sets in motion routine creation. First, it would provide information on what the routine is; second, it could be used to develop a conceptual design and elaboration of useful resources.

The situated nature of our case that provides an account of routine creation in a context where both the firm and its environment are in a process of change constitutes both a research strength but also a limitation. Theoretical generalization requires more qualitative research in other settings and industries to understand the variety of situated expressions of routine creation and how entrepreneurial actions and artefacts are used in those contexts. 
Finally, another important contribution to the routines debate is in working at the intersection of the practice and capability schools to build a conversation with diverse concepts from these literature streams (Kay 2018) and to try to combine them in a new model. We believe that this combination provides a richer framework for understanding the difficulties faced by start-ups during the creation of routines, which are critical for their survival. By doing so, we provide a processual approach to entrepreneurship that reveals some ordinary activities that are required to build micro capabilities. The novelty of the field (bio pesticides) illustrates, also, why such ordinary activities can become complex in the absence of internal firm knowledge which must be identified, accumulated and negotiated with external actors.

Compliance with Ethical Standards:

Funding: none

Conflict of Interest: The authors declare that they have no conflict of interest.

JEL Code: L21, L22, L26, M13, O33 


\section{References}

Aldrich HE, Martinez MA (2001) Many are called, but few are chosen: An evolutionary perspective for the study of entrepreneurship. Entrep Theory Pract 25:41-56. doi: 10.1177/104225870102500404

Aldrich HE, Yang T (2014) How do entrepreneurs know what to do? Learning and organizing in new ventures. J Evol Econ 24:59-82. doi: 10.1007/s00191-013-0320-x

Baker T, Nelson RE (2005) Creating something from nothing: Resource construction through entrepreneurial bricolage. Adm Sci Q 50:329-366. doi: 10.2189/asqu.2005.50.3.329

Bapuji H, Hora M, Saeed AM (2012) Intentions, intermediaries, and interaction: Examining the emergence of routines. J Manag Stud 49:1586-1607. doi: 10.1111/j.1467-6486.2012.01063.x

Becker MC, Knudsen T, March JG (2006) Schumpeter, Winter, and the sources of novelty. Ind Corp Change 15:353371. doi: $10.1093 / \mathrm{icc} / \mathrm{dt} 1003$

Bertels S, Howard-Grenville J, Pek S (2016) Cultural molding, shielding, and shoring at Oilco: The role of culture in the integration of routines. Organ Sci 27:573-593. doi: 10.1287/orsc.2016.1052

Bucher S, Langley A (2016) The interplay of reflective and experimental spaces in interrupting and reorienting routine dynamics. Organ Sci 27:594-613. doi: 10.1287/orsc.2015.1041

Busenitz LW, West GP, Shepherd D, et al (2003) Entrepreneurship research in emergence: Past trends and future directions. J Manag 29:285-308. doi: 10.1016/S0149-2063_03_00013-8

Cacciatori E (2012) Resolving conflict in problem-solving: Systems of artefacts in the development of new routines. J Manag Stud 49:1559-1585. doi: 10.1111/j.1467-6486.2012.01065.x

Casson M (1982) The entrepreneur: An economic theory. Rowman \& Littlefield

Chandler D, Bailey AS, Tatchell GM, et al (2011) The development, regulation and use of biopesticides for integrated pest management. Philos Trans R Soc Lond B Biol Sci 366:1987-1998. doi: 10.1098/rstb.2010.0390

Charmaz K (2006) Constructing grounded theory: A practical guide through qualitative analysis. Sage

Cohen MD (2007) Reading Dewey: Reflections on the study of routine. Organ Stud 28:773-786. doi: $10.1177 / 0170840606077620$

Cohen MD, Bacdayan P (1994) Organizational routines are stored as procedural memory: Evidence from a laboratory study. Organ Sci 5:554-568

Cohen MD, Burkhart R, Dosi G, et al (1996) Routines and other recurring action patterns of organizations: Contemporary research issues. Ind Corp Change 5:653-698. doi: 10.1093/icc/5.3.653

Comeche JM, Loras J (2010) The influence of variables of attitude on collective entrepreneurship. Int Entrep Manag J 6:23-38. doi: 10.1007/s11365-009-0131-6

Cyert RM, March JG (1963) A behavioral theory of the firm. Prentice-Hall

D'Adderio L (2011) Artifacts at the centre of routines: Performing the material turn in routines theory. J Institutional Econ 7:197-230. doi: 10.1017/S174413741000024X

D'Adderio L (2008) The performativity of routines: Theorising the influence of artefacts and distributed agencies on routines dynamics. Res Policy 37:769-789. doi: 10.1016/j.respol.2007.12.012 
D'Adderio L (2014) The replication dilemma unravelled: How organizations enact multiple goals in routine tansfer. Organ Sci 25:1325-1350. doi: 10.1287/orsc.2014.0913

Davies A, Frederiksen L, Cacciatori E, Hartmann A (2018) The long and winding road: Routine creation and replication in multi-site organizations. Res Policy 47:1403-1417. doi: 10.1016/j.respol.2018.04.016

Desa G (2012) Resource mobilization in international social entrepreneurship: Bricolage as a mechanism of institutional transformation. Entrep Theory Pract 36:727-751. doi: 10.1111/j.1540-6520.2010.00430.x

Di Domenico M, Haugh H, Tracey P (2010) Social bricolage: Theorizing social value creation in social enterprises. Entrep Theory Pract 34:681-703

Dionysiou DD, Tsoukas H (2013) Understanding the (re)creation of routines from within: A symbolic interactionist perspective. Acad Manage Rev 38:181-205. doi: 10.5465/amr.2011.0215

Dittrich K, Guérard S, Seidl D (2016) Talking about routines: The role of reflective talk in routine change. Organ Sci 27:678-697. doi: 10.1287/orsc.2015.1024

Dittrich K, Seidl D (2017) Emerging Intentionality in Routine Dynamics: A Pragmatist View. Acad Manage J 61:111138. doi: 10.5465/amj.2015.0010

Duymedjian R, Rüling C-C (2010) Towards a foundation of bricolage in organization and management theory. Organ Stud 31:133-151. doi: 10.1177/0170840609347051

Edmondson AC, Bohmer RM, Pisano GP (2001) Disrupted routines: Team learning and new technology implementation in hospitals. Adm Sci Q 46:685. doi: 10.2307/3094828

Emirbayer M, Mische A (1998) What is agency? Am J Sociol 103:962-1023. doi: 10.1086/231294

Feldman MS (2016) Routines as process: Past, present, and future. In: Howard-Grenville J, Rerup C, Langley A, Tsoukas $\mathrm{H}$ (eds) Organizational routines: How they are created, maintained, and changed. Oxford University Press, New York, NY, p 267

Feldman MS (2000) Organizational routines as a source of continuous change. Organ Sci 11:611-629. doi: 10.1287/orsc.11.6.611.12529

Feldman MS, Pentland BT (2003) Reconceptualizing organizational routines as a source of flexibility and change. Adm Sci Q 48:94-118. doi: 10.2307/3556620

Feldman MS, Pentland BT, D'Adderio L, Lazaric N (2016) Beyond routines as things: Introduction to the special issue on routine dynamics. Organ Sci 27:505-513. doi: 10.1287/orsc.2016.1070

Felin T, Foss NJ (2009) Organizational routines and capabilities: Historical drift and a course-correction toward microfoundations. Scand J Manag 25:157-167. doi: 10.1016/j.scaman.2009.02.003

Garud R, Karnøe P (2003) Bricolage versus breakthrough: Distributed and embedded agency in technology entrepreneurship. Res Policy 32:277-300. doi: 10.1016/S0048-7333(02)00100-2

Glaser VL (2017) Design performances: How organizations inscribe artifacts to change routines. Acad Manage J 60:2126-2154. doi: 10.5465/amj.2014.0842

Greve HR (2008) Organizational routines and performance feedback. In: Becker MC (ed) Handbook of organizational routines. Edward Elgar Publishing Limited, Northampton, pp 187-204

Gupta A, Hoopes DG, Knott AM (2015) Redesigning routines for replication. Strateg Manag J 36:851-871. doi: 10.1002/smj.2254 
Halme M, Lindeman S, Linna P (2012) Innovation for inclusive business: Intrapreneurial bricolage in multinational corporations. J Manag Stud 49:743-784. doi: 10.1111/j.1467-6486.2012.01045.x

Handford CE, Elliott CT, Campbell K (2015) A review of the global pesticide legislation and the scale of challenge in reaching the global harmonization of food safety standards. Integr Environ Assess Manag. doi:

10.1002/ieam.1635

Howard-Grenville JA (2005) The persistence of flexible organizational routines: The role of agency and organizational context. Organ Sci 16:618-636. doi: 10.1287/orsc.1050.0150

Howard-Grenville JA, Rerup C, Langley A, Tsoukas H (2016) Organizational routines: How they are created, maintained, and changed. Oxford University Press, New York, NY

Janssen F, Fayolle A, Wuilaume A (2018) Researching bricolage in social entrepreneurship. Entrep Reg Dev 30:450470. doi: 10.1080/08985626.2017.1413769

Jarzabkowski P, Bednarek R, Spee P (2016) The role of artifacts in stablishing connectivity within professional routines: A question of entanglement. In: Howard-Grenville J, Rerup C, Langley A, Tsoukas H (eds) Organizational routines: How they are areated, maintained, and changed. Oxford University Press, p 240

Kay NM (2018) We need to talk: opposing narratives and conflicting perspectives in the conversation on routines. Ind Corp Change 27:943-956. doi: 10.1093/icc/dty025

Labatut J, Aggeri F, Girard N (2012) Discipline and change: How technologies and organizational routines interact in new practice creation. Organ Stud 33:39-69. doi: 10.1177/0170840611430589

Langley, A. (1999). Strategies for theorizing from process data. Acad Manag R, 24(4), 691-710. https://doi.org/10.2307/259349

Lazaric N, Denis B (2005) Routinization and memorization of tasks in a workshop: The case of the introduction of ISO norms. Ind Corp Change 14:873-896. doi: 10.1093/icc/dth074

Lazaric N, Mangolte P-A, Massué M-L (2003) Articulation and codification of collective know-how in the steel industry: Evidence from blast furnace control in France. Res Policy 32:1829-1847. doi: 10.1016/S00487333(03)00066-0

Levi-Strauss C (1966) The savage mind. University of Chicago Press, Chicago

Linna P (2013) Bricolage as a means of innovating in a resource-scarce environment: A study of innovatorentrepreneurs at the BOP. J Dev Entrep 18:1350015. doi: 10.1142/S1084946713500155

Lorino P (2018) Pragmatism and Organization Studies, Oxford University Press

Low MB, MacMillan IC (1988) Entrepreneurship: Past research and future challenges. J Manag 14:139-161. doi: $10.1177 / 014920638801400202$

March JG, Simon HA (1958) Organizations, Wiley. New York, NY

Mathews JA (2010) Lachmannian insights into strategic entrepreneurship: Resources, activities and routines in a disequilibrium world. Organ Stud 31:219-244. doi: 10.1177/0170840609347044

Maxwell JA, Miller BA (2008) Categorizing and connecting strategies in qualitative data analysis. In: Hesse-Biber SN, Leavy P (eds) Handbook of emergent methods. The Guilford Press, New York, NY, pp 461-477 
McMullen JS, Shepherd DA (2006) Entrepreneurial action and the role of uncertainty in the theory of the entrepreneur. Acad Manage Rev 31:132-152. doi: 10.5465/AMR.2006.19379628

Miller KD, Pentland BT, Choi S (2012) Dynamics of performing and remembering organizational routines: Performing and remembering organizational toutines. J Manag Stud 49:1536-1558. doi: 10.1111/j.1467-

6486.2012.01062.x

Minniti M, Bygrave W (2001) A dynamic model of entrepreneurial learning. Entrep Theory Pract 25:5-16. doi: $10.1177 / 104225870102500301$

Nelson RR, Winter SG (1982) An evolutionary theory of economic change. Harvard University Press, Cambridge

Orlikowski WJ (2007) Sociomaterial practices: Exploring technology at work. Organ Stud 28:1435-1448. doi: $10.1177 / 0170840607081138$

Orlikowski WJ (1992) The duality of technology: Rethinking the concept of technology in organizations. Organ Sci 3:398-427. doi: 10.1287/orsc.3.3.398

Parker SC (2011) Intrapreneurship or entrepreneurship? J Bus Ventur 26:19-34. doi: 10.1016/j.jbusvent.2009.07.003

Parmentier Cajaiba A (2018) Le Dialogue Comme Vecteur d'Actions et de Connaissances Orientées Stratégie. In: Stratégie Organisationnelle par le Dialogue, Economica. Paris, pp 124-134

Parmigiani A, Howard-Grenville J (2011) Routines revisited: Exploring the capabilities and practice perspectives. Acad Manag Ann 5:413-453. doi: 10.1080/19416520.2011.589143

Pentland BT (2011) The foundation is solid, if you know where to look: Comment on Felin and Foss. J Institutional Econ 7:279-293. doi: 10.1017/S174413741000041X

Pentland BT, Feldman MS, Becker MC, Liu P (2012) Dynamics of organizational routines: A generative model. J Manag Stud 49:1484-1508. doi: 10.1111/j.1467-6486.2012.01064.x

Pentland BT, Rueter HH (1994) Organizational routines as grammars of action. Adm Sci Q 484-510. doi: $10.2307 / 2393300$

Phillips DJ (2005) Organizational genealogies and the persistence of gender inequality: The case of Silicon Valley law firms. Adm Sci Q 50:440-472. doi: 10.2189/asqu.2005.50.3.440

Possas ML, Salles-Filho S, Silveira JM da (1996) An evolutionary approach to technological innovation in agriculture: Some preliminary remarks. Res Policy 25:933-945. doi: 10.1016/0048-7333(96)00884-0

Rerup C, Feldman MS (2011) Routines as a source of change in organizational schemata: The role of trial-and-error learning. Acad Manage J 54:577-610. doi: 10.5465/AMJ.2011.61968107

Salvato C (2009) Capabilities unveiled: The role of ordinary activities in the evolution of product development processes. Organ Sci 20:384-409. doi: 10.1287/orsc.1080.0408

Salvato C, Rerup C (2011) Beyond collective entities: multilevel research on organizational routines and capabilities. J Manag 37:468-490. doi: 10.1177/0149206310371691

Senyard J, Baker T, Davidsson P (2009) Entrepreneurial bricolage: Towards systematic empirical testing. Front Entrep Res 29:5

Shani AB, Mohrman SA, Pasmore WA, et al (2007) Handbook of collaborative management research. Sage

Sharma P, Chrisman SJJ (1999) Toward a reconciliation of the definitional issues in the field of corporate entrepreneurship. Entrep Theory Pract 23:11-27 
Simpson B, Lorino P (2016) Re-viewing routines through a pragmatist lens. In: Howard-Grenville JA, Rerup C, Langley

A, Tsoukas $\mathrm{H}$ (eds) Organizational routines: How they are created, maintained, and changed. Oxford University Press, New York, NY

Stevenson HH, Jarillo JC (1990) A paradigm of entrepreneurship: Entrepreneurial management. Strateg Manag J 11:17-27

Stinchcombe AL (1965) Social structure and organizations. In: March JG (ed) Handbook of Organizations. : Rand McNally, Chicago, pp 142-169

Tell F (2013) Knowledge articulation. Palgrave Encycl. Strateg. Manag. 1-5

Tsoukas H, Chia R (2002) On organizational becoming: Rethinking organizational change. Organ Sci 13:567-582

Turner SF, Rindova V (2012) A balancing act: How organizations pursue consistency in routine functioning in the face of ongoing change. Organ Sci 23:24-46. doi: 0.1287/orsc.1110.0653

Vanevenhoven J, Winkel D, Malewicki D, et al (2011) Varieties of bricolage and the process of entrepreneurship. N Engl J Entrep 14:53-66. doi: 10.1108/NEJE-14-02-2011-B005

Vanloqueren G, Baret PV (2009) How agricultural research systems shape a technological regime that develops genetic engineering but locks out agroecological innovations. Res Policy 38:971-983. doi: 10.1016/j.respol.2009.02.008

Winter S, Teece DJ (1998) Knowledge and competence as strategic assets. In: Klein DA (ed) The strategic management of intellectual capital. Routledge, Woburn

Winter SG (2003) Understanding dynamic capabilities. Strateg Manag J 24:991-995. doi: 10.1002/smj.318

Winter SG, Szulanski G (2001) Replication as strategy. Organ Sci 12:730-743. doi: 10.1287/orsc.12.6.730.10084

Witell L, Gebauer H, Jaakkola E, et al (2017) A bricolage perspective on service innovation. J Bus Res 79:290-298. doi: 10.1016/j.jbusres.2017.03.021

Zahra SA (1993) A conceptual model of entrepreneurship as firm behavior: A critique and extension. Entrep Theory Pract 17:5-21. doi: 10.1177/104225879101600102

Zbaracki MJ, Bergen M (2010) When truces collapse: A longitudinal study of price-adjustment routines. Organ Sci 21:955-972. doi: doi.org/10.1287/orsc.1090.0513 
Figure

Figure 1: 3-Phase model of routine creation: Scanning - Performing - Adopting

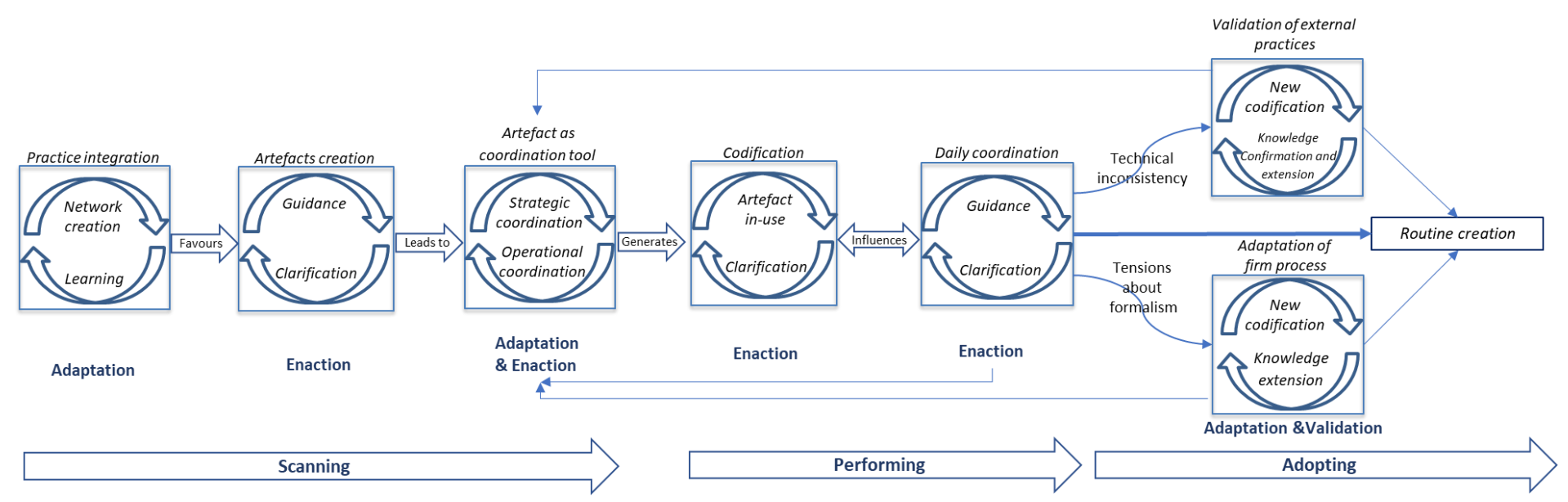




\section{Tables}

Table 1: Field/research consistency

Agronate

Biopesticide, emerging field

\section{Consistency with research question}

Adapted to observe creation and modification of routines

Easiness to identify and trace back mechanisms

Routines make sense in regard to the firm's strategic goal products.

$\begin{array}{ll}\begin{array}{l}\text { Strategy } \\ \text { discourse }\end{array} & \begin{array}{l}\text { Growth based on two pillars: commercial } \\ \text { development and European approval of } \\ \text { products. }\end{array}\end{array}$

Levels of Changes at the industry level
analysis Changes at the firm level

Routines developed in the firm is also new at the industry level.

$\begin{array}{ll}\text { Type of } & - \text { CEO } \\ \text { practitioner } & \text { - Registration, production VP } \\ & - \text { Marketing Managing Director } \\ & - \text { Experts : registration consultant and } \\ & \text { authorities }\end{array}$

Various level of analysis concerning origins of routines, their use and reorganization. 
Table 2: codification tree and phases: Scanning

\begin{tabular}{|c|c|c|}
\hline Verbatim Summaries & Themes & Abstract codes \\
\hline "Looking for potential change in regulatory arena" & \multirow[b]{2}{*}{ Information search } & \multirow{3}{*}{ Learning } \\
\hline $\begin{array}{c}\text { "Looking for precise regulatory information related to } \\
\text { their class of product" }\end{array}$ & & \\
\hline "Identification of possible actions and tools" & Mapping registration & \\
\hline "Tentative use of registration tools" & $\begin{array}{l}\text { Registration practices in } \\
\text { action }\end{array}$ & Practices integration \\
\hline "Contacting new person/institution" & Network creation & Network creation \\
\hline "Development of tools and registration dossier" & $\begin{array}{c}\text { Creation of a pool of } \\
\text { activity-specific artefact }\end{array}$ & \multirow{2}{*}{ Artefacts creation } \\
\hline $\begin{array}{l}\text { "Diffusion of base artefact to top management and } \\
\text { teams" }\end{array}$ & Diffusion of artefacts & \\
\hline "Questions raised by core dossier creation" & $\begin{array}{c}\text { Artefact questions current } \\
\text { firm activity }\end{array}$ & \multirow{2}{*}{ Clarification } \\
\hline $\begin{array}{c}\text { "Providing information about registration process and } \\
\text { practices to top management" }\end{array}$ & $\begin{array}{l}\text { Supporting strategic } \\
\text { decision making }\end{array}$ & \\
\hline "Finding information to facilitate registration" & $\begin{array}{l}\text { Identifying resources to } \\
\text { register }\end{array}$ & Guidance \\
\hline "Associate usual activities to new artefacts" & $\begin{array}{l}\text { Link registration with firm } \\
\text { activity }\end{array}$ & $\begin{array}{c}\text { Artefact as } \\
\text { coordination support }\end{array}$ \\
\hline "Transmission of refined information and artefacts" & Orienting operations & \multirow{2}{*}{$\begin{array}{l}\text { Operational } \\
\text { coordination }\end{array}$} \\
\hline "Follow up with scientific and production teams" & Informal supervision & \\
\hline "Organizing task force meetings" & New working unit creation & \multirow[b]{2}{*}{ Strategic coordination } \\
\hline "Suggesting priority to scientific team" & $\begin{array}{l}\text { Modification of strategic } \\
\text { priorities }\end{array}$ & \\
\hline
\end{tabular}


Table 2 (cont'd.): Performing and adoping

\begin{tabular}{|c|c|c|}
\hline Verbatim Summaries & Themes & Abstract codes \\
\hline $\begin{array}{c}\text { "Explanation of specific document structures and } \\
\text { authorities perspective" }\end{array}$ & $\begin{array}{l}\text { Overall precision on } \\
\text { registration }\end{array}$ & Clarification \\
\hline $\begin{array}{l}\text { "Seeking practical information from experts and regulators } \\
\text { to implement the activity" }\end{array}$ & Looking for practical tips & Guidance \\
\hline "Use of artefact with external actors to fill the gaps" & Artefact in situation & \multirow{2}{*}{ Artefact in use } \\
\hline "Sharing new activity artefact to impulse new activity" & $\begin{array}{l}\text { Artefact to support activity } \\
\text { realisation }\end{array}$ & \\
\hline "Identification of the scientific lack to achieve dossier" & Registration - firm work gap & \multirow{3}{*}{ Codification } \\
\hline "Looking for missing data externally" & $\begin{array}{l}\text { Looking for adapted } \\
\text { knowledge }\end{array}$ & \\
\hline $\begin{array}{c}\text { "Identification of in-house studies content that supports } \\
\text { regulatory demand" }\end{array}$ & Registration-firm fits & \\
\hline "Checking in-house production of document" & Verifying content production & \multirow{3}{*}{ Daily coordination } \\
\hline $\begin{array}{l}\text { "Formal demand for modifying in-house studies to fit } \\
\text { authorities demands }\end{array}$ & \multirow{2}{*}{$\begin{array}{l}\text { Intervention into firms } \\
\text { activities }\end{array}$} & \\
\hline $\begin{array}{l}\text { "Chunks of generic registration document filled by } \\
\text { competent agent" }\end{array}$ & & \\
\hline $\begin{array}{c}\text { "Creation of specific documents to value in-house scientific } \\
\text { work" }\end{array}$ & Specific artefact creation & \multirow{2}{*}{ New codification } \\
\hline $\begin{array}{l}\text { "Articulating and presenting in-house findings to fit } \\
\text { regulatory requirements" }\end{array}$ & $\begin{array}{l}\text { New way to formalize in- } \\
\text { house research }\end{array}$ & \\
\hline $\begin{array}{c}\text { "Checking fit between in-house and external scientific } \\
\text { work" }\end{array}$ & Extending firm knowledge & \multirow{2}{*}{$\begin{array}{l}\text { Firm knowledge } \\
\text { extension }\end{array}$} \\
\hline $\begin{array}{c}\text { "Transdisciplinary conversations to advance on-going } \\
\text { project registration" }\end{array}$ & $\begin{array}{l}\text { Joint activity to guide } \\
\text { knowledge production }\end{array}$ & \\
\hline $\begin{array}{c}\text { "Conversing with external person (authorities or consultant) } \\
\text { to validate actions" }\end{array}$ & $\begin{array}{l}\text { Verifying robustness of } \\
\text { knowledge elaborated }\end{array}$ & Knowledge confirmation \\
\hline
\end{tabular}


